\title{
Meio Ambiente, Leis e Agricultura Familiar: Relações e consequências.
}

\begin{abstract}
RESUMO: Assim como diversas espécies possuem mecanismos e estratégias de sobrevivência e prosperidade, a espécie humana também criou estratégias para prosperar e reproduzir em seu ambiente. Entre eles o trabalho coletivo e familiar, transmissão de conhecimentos ancestrais e científicos e leis e regras para organizar e harmonizar interesses antagônicos. Entretanto é notório que algum descompasso está acontecendo nessas relações, já que estamos vivenciando um período de degradação acentuada do ambiente, das relações familiares e sociais. O presente trabalho tenta entender como se dá tais relações, quais suas causas e consequências e se aprofunda no fenômeno da agricultura familiar e do agronegócio. Também se aprofunda na análise normativa e quantitativa de como as leis estão sendo usadas para compreender e potencializar o fenômeno específico da agricultura familiar e do meio ambiente.
\end{abstract}

Palavras-chaves: Agricultura familiar. Leis. Meio Ambiente.

\section{Environment, Law and Family Agriculture: Relations and consequences.}

\begin{abstract}
Just as diverse species possess mechanisms and strategies for survival and prosperity, the human species has also created strategies to thrive and reproduce in its environment. These include collective and family work, the transmission of ancestral and scientific knowledge, and laws and rules to organize and harmonize antagonistic interests. However, it is notorious that some mismatch is happening in these relationships, since we are experiencing a period of marked degradation of the environment, family and social relations. The present work tries to understand how these relations take place, what their causes and consequences are and delves into the phenomenon of family farming and agribusiness. It also delves into the normative and quantitative analysis of how laws are being used to understand and potentiate the specific phenomenon of family farming and the environment.
\end{abstract}

Keywords: Family agriculture. Laws. Environment. 


\section{INTRODUÇÃO}

Existe uma relação de simbiose entre a comunidade, o meio ambiente e leis. Assim como mais uma espécie que vive e tenta prosperar em determinado ambiente, nossa espécie humana tenta também criar um ambiente de prosperidade onde vive. Entretanto, nossa visão limitada e por vezes influenciada por erradas questões sociais e de um profundo egoísmo acaba gerando frutos perniciosos. Os resultados mais notórios disso são nossas leis e os resultados consequentes dela. No presente trabalho tentamos entender o fenômeno da agricultura familiar em contraposição ao agronegócio em larga escala, suas relações com o meio ambiente e as leis decorrentes desse embate. Temos como objetivo geral tentar entender as relações entre os aspectos citados $\mathrm{e}$ as decorrentes leis surgidas como consequência. Queremos demonstrar especificamente que uma visão científica limitada da questão agrária e ambiental acaba gerando leis elitistas, pouco produtivas e na contramão das necessidades naturais e comunitárias. P.ex., demonstraremos em pesquisas normativas, que uma visão limitada da ciência agrária, baseada em buscas elitistas da produção do agronegócio, acabou gerando um número de leis que só favorecem um dos aspectos da agricultura, enfraquecem a agricultura familiar e é contraprodutiva aos interesses naturais.

Nossa justificativa para escolha do tema vem de uma sincera preocupação dos rumos que o Brasil toma em relação à utilização do seu meio ambiente, seus resultados nas comunidades e seus efeitos sociais. É necessário aprofundar tais estudos para construir uma reorientação de buscas científicas, normativas e sociais, que consigam geram uma maior prosperidade ambiental e humana.

O trabalho está dividido em duas partes delimitadas, onde na primeira enfrenta-se o problema apresentado e na segunda apresenta-se alguns estudos normativos e quantitativos, para corroborar as linhas argumentativas apresentadas.

\section{MATERIAL E MÉTODO}


Meio ambiente, leis e comunidade estão mais conectados e se influenciam mais do que aparentam. Delimitando essa busca, vamos nos focar em comunidades baseadas em na agricultura familiar, observando seus delineamentos, suas características e sua importância para o País. Mitos forjados ao longo do tempo são apontados e analisados; aqui, procura-se mostrar que sua superação é essencial para um tratamento maduro e científico do tema.

Longe de se deter nos meandros conceituais da agricultura familiar, esse trabalho procura apresentar pontos considerados históricos dentro da evolução da agronomia familiar. Ao mesmo tempo, defende 0 argumento de que as transformações estruturais ocorridas desde os anos 1960 prepararam o terreno para modificações no esquema produtivo, denominado de novo "estilo de pensamento", com expoente acadêmicos como Ivan Sergio Freire de Sousa ${ }^{1}$ e José Renato Figueira Cabral ${ }^{2}$

O significado de "estilo de pensamento" será enfrentado mais adiante, a partir das contribuições de Fleck ${ }^{3}$ para metodologia científica. Iremos defender que uma série de práticas e comportamentos da agricultura familiar estão gerando profundas modificações nas ciências e nas leis, assim como novos desafios ambientais estão impondo novos resultados e métodos. Devemos partir para novos paradigmas onde a ciência, a comunidade, suas leis e o meio ambiente estejam alinhados em suas buscas e resultados, percebendo que não há evolução sem que todos se beneficiem da interação mútua.

Argumenta-se que o uso de sementes, as informações sobre espaçamento e épocas de plantio, as formas de tratos culturais, a colheita e o armazenamento tudo incorpora informações técnico-científicas, mas também que essas observações científicas partiram da observação da própria natureza e das soluções que as comunidades ancestrais já praticam há séculos. Na verdade é um contraste artificial imaginar que há divisões estanques entre os três elementos. Eles integram-se e

\footnotetext{
${ }^{1}$ SOUSA IVAN SÉRGIO FREIRE DE. A sociedade, o cientista e o problema de pesquisa: o caso do setor público agrícola brasileiro. Tradução . [s.I.] Ed. Hucitec, 1993. 2 SOUZA IVAN SÉRGIO FREIRE.; CABRAL JOSÉ RENATO FIGUEIRA. Ciência como instrumento de inclusão social. Tradução . [s.I.] Embrapa Informação Tecnológica, 2009..

${ }^{3}$ CONDÉ MAURO LÚCIO LEITÃO. Ludwik Fleck: estilos de pensamento na ciência. Tradução . [s.I.] FT, Fino Traço Editora Ltda., 2012..
} 
somam-se. Por vezes essa relação é benéfica e sintrópica (na medida de trocas equilibradas de energia) e por vezes ela é entrópica, como nos ensinamentos de Ernst Gotsch ${ }^{4}$

É notória uma modernização de processos e técnicas, mas essa "modernização" ainda é seletiva. Instalada no País no começo do século 19, sedimentando sua marca de exclusão por abranger uma agricultura de elites com produtos destinados à exportação e manutenção das grandes fortunas do Café, da Cana e Pecuária. Também é notório como essas técnicas não geraram inclusão social, já que o pequeno agricultor familiar não era o centro dos interesses agrônomos científicos tradicionais.

Nunca devemos olvidar que a relação entre esses três elementos (meio ambiente,comunidade e leis) são os que mais profundas transformações que colocam suas marcas em todas as esferas. Perdeu-se a consciência que o ato de se alimentar ainda é a base de todas as outras e vive-se hoje na ilusão da abundância.

Para se enfrentar os citados desafios, o presente texto está organizado em duas partes. A primeira faz uma introdução ao tema da agricultura familiar, recapitulando alguns dos momentos históricos de teorização, questionando alguns mitos e identificando algumas premissas.

A segunda discute resumidamente as relações entre ciência, natureza e leis, mostrando que o meio ambiente apresenta diversos cenários e desafios e para eles há séculos, de maneira criativa e científica, tentamos encontrar soluções.

A espécie humana é uma apaixonada por problemas e soluções. Nosso pensamento abstrato e criativo é um dos trunfos de nossa espécie. Entretanto essas soluções e técnicas acabam gerando efeitos inesperados e toda mudança técnica acaba também gerando mudanças sociais. P.ex., o desenvolvimento de melhores técnicas de destilação do caldo da cana de açúcar em Álcool é que permitiu uma dominação social e política de um pequeno grupo de proprietários de terra frente a toda uma população de trabalhadores e isso acabou reverberando em leis que defendeu e potencializou essa indústria em específico.

\footnotetext{
${ }^{4}$ GÖTSCH ERNST. Break-through in agriculture. Tradução . [s.I.] AS-PTA, 1995.
} 
Sempre devemos observar que a agricultura brasileira engloba inúmeras agriculturas, todas igualmente importantes para o desenvolvimento do País. Cada uma com desafios próprios. Elas, longe de serem estanques, são complementares e interdependentes. Diferenciam-se pelas situações ambientais, momentos históricos e configurações socioculturais e econômicas.

Cada tipo de agricultura - isolada ou conjuntamente - moldou a variedade de nosso mercado, nosso atual estado ambiental e o próprio povo brasileiro e suas leis.

No conglomerado de agriculturas praticadas no Brasil está a agricultura familiar, que, de maneira diferenciada, encontra-se em todo o território nacional, sendo a principal base alimentar da população brasileira.

Por ser tão extensa e atuante em tão diversos ecossistemas, é uma atividade complexa e está longe de ser homogênea. Por isso, ela foi, ao longo do tempo, tanto teorizada quanto mistificada. Alguns autores abordaram essa temática com brilhantismo, como Schneider ${ }^{5}$, Abramovay ${ }^{6}$, Shenton ${ }^{7}$.

Em toda literatura observamos como não é pacífico o conceito de agricultura familiar. Inclusive com forte viés político, escritores como Lênin ${ }^{8}$ abordaram a temática como mais uma das frentes de batalha entre o capital e o povo. No campo está mais um local de embate entre capital e trabalhadores, em que o primeiro tipo é empreendido pelo proprietário dos meios de produção, e o segundo é caracterizado pela presença do trabalhador assalariado. Nessa obra, que mostra a ruína da produção camponesa na Rússia e sua crescente desvantagem dentro da lógica da mecanização, onde a atenção é primariamente dirigida ao fenômeno da expansão do capitalismo e dos lucros e não da qualidade de vida comunitária e ambiental.

Foi, entretanto, nas décadas iniciais do século 20 que os primeiros estudos realmente importantes, no que diz respeito ao entendimento da agricultura familiar, começaram a florescer. A Teoria da Economia Camponesa, de Alexander Vasilevich

\footnotetext{
${ }^{5}$ SCHNEIDER, J. E. Integração de mercados e desafios para a pesquisa agropecuária Mercosul e União Européia. Tradução . [s.I.] EMBRAPA-CPACT, 1995.

${ }^{6}$ BITTENCOURT, G. A.; ABRAMOVAY, R. Inovações institucionais no financiamento à agricultura familiar: o sistema Cresol. Tradução . [s.I.] Oficina Regional para América Latina y el Caribe, 2002.

${ }^{7}$ MALUF, Renato Sérgio. Resenha Bibliográfica 1 - Portal de Revistas da USP. Disponível em: https://www.revistas.usp.br/ee/article/viewFile/117065/114680. Acessado em 10 out. 2018. ${ }^{8}$ GONCHAROV, A. D.; LUNIAKOV, P. I. V.I. Lenin y el campesinado: compendio histórico de divulgación. Traducao . [s.I.] Agencia de Prensa Nóvosti, 1969.
} 
Chayanov $^{9}$, é um desses. Entre 1919 e 1930, esse autor não só sistematizou as discussões anteriores sobre o assunto, como terminou por desenvolver uma contribuição original. Infelizmente só analisando a situação de agricultores russos, perdendo assim uma visão global e sistêmica, Chayanov trabalha com unidades de produção familiar camponesa. Ele vê essas unidades de produção como uma forma econômica distinta da produção capitalista na agricultura. Mais do que isso, a originalidade de seu trabalho está em procurar demonstrar que a produção familiar camponesa continua com suas características essenciais (basicamente o trabalho familiar), mesmo que inserida em situações diversas. Essas unidades são a base de das famílias, alianças e forma de organização social.

Leis que regulam o patrimônio, a família e o meio ambiente surgem para trazer estabilidade produtiva nessas unidades de produção agrícola. Há também o exemplar trabalho de Friedmann $^{10}$, que estudam esse tipo de produção em sociedades altamente industrializadas, como é o caso dos Estados Unidos.

Nas primeiras décadas do século 20 , um dos pioneiros nessa denominação foi Kautsky ${ }^{11}$, na sua obra originalmente chamada Die Agrarfrage (A questão agrária), já que para esses filósofos a questão agrária, familiar e Estatal estava totalmente unidas. No Brasil, os trabalhos sobre agricultura familiar ganharam popularidade entre os estudiosos, principalmente na época quando os movimentos políticos do campo começaram a se tornar o centro das preocupações Estatais. Não devemos esquecer que em Cuba p.ex., a revolução comunista foi em grande parte apoiada por camponeses.

Um fato de difícil solução é chegar a um conceito de camponês, já que sob essa palavra já viveram trabalhadores do mundo antigo, medieval, feudal e moderno. Portanto, muitas formas de relações de trabalho e relações ambientais, em tempos e circunstâncias diversas, todas sob o mesmo signo.

\footnotetext{
${ }^{9}$ ČAJANOV ALEKSANDR VASILJEVIČ; SCHULZE, E.; SCHLICHTER, M. Alexander Vasilievich Chayanov: the tragedy of an outstanding agricultural economist. Traducao . [s.I.] AgriMedia, 2003.

${ }^{10} \mathrm{R}$. TATIANA LÓPEZ; FRIEDMANN, A. Análisis presupuestario del Ministerio de Agricultura y Ganadería 1998 al 2000. Tradução . [s.I.] CEPPRO, 2001.

${ }^{11}$ KAUTSKY, K.; BAYO, C.; UNAMUNO, M. D. E. La Cuestión agraria: (Die agrarfrage). Tradução . [s.l.] Viuda de Rodríguez Serra, 1903.
} 
O presente trabalho tenta entender como essas questões acabaram gerando leis que abrangiam esses desafios e buscas. Por exemplo, podemos partir de um conceito de agricultura familiar dado pela Lei da Agricultura Familiar (Lei $n^{0} 11.322$, de 24 de julho de 2006). Nela, define-se o agricultor familiar como aquele que pratica atividades no meio rural, atendendo, simultaneamente, a quatro requisitos: a) não ter, a qualquer título, área maior do que quatro módulos fiscais; b) utilizar principalmente mão-de-obra da própria família nas atividades econômicas do seu estabelecimento; c) ter renda familiar predominantemente originada de atividades econômicas vinculadas ao próprio estabelecimento; d) dirigir o estabelecimento com sua família. Essa definição é utilizada não apenas por ser lei, mas porque foi amplamente discutida por especialistas conhecedores dos principais debates teóricos sobre o tema. Trata-se de um norte para direcionar que esteja analisando o caso concreto. Por limitado que possa ser, não se afasta daquilo que é básico. A utilização desse conceito faz, por força das estatísticas, emergir um grande número de pessoas que tem a agricultura como fonte de sustento e de sentido para seu modo de vida. Dedicam-se à agricultura como profissão e estilo de vida e também expressão cultural e comunitária. Eles residem na propriedade ou moram perto dela, e tiram seu sustento e local na comunidade através do que produzem. Também podem ser estratificados em categorias. Cultivam desde um produto para exportação até dezenas de produtos para consumo próprio e do mercado local. Muitos outros nem produzem o suficiente para sobreviver, tendo de se vincular a atividades não agrícolas para complementar a renda familiar. De qualquer ângulo que se observe esse contingente de pessoas, um dos aspectos bem característicos é a ampla diferenciação. Diferem no que produzem, como produzem e onde produzem. Distinguem-se também quanto ao uso de tecnologia e às relações entre vizinhos, com o mercado e estado.

Estudo relativamente recente do Professor J. Sobrinho ${ }^{12}$ identificou, na região do Semi-Árido brasileiro, a existência de doze tipos diferentes de produção familiar:

\footnotetext{
${ }^{12}$ SOBRINHO J. FALCÃO. Semi-árido diversidades, fragilidades e potencialidades. Tradução . [s.l.] Sobral Gráfica, 2006.
} 
"agricultura de sobrevivência, agricultura de subsistência, pecuária de subsistência, agricultura comercial, agricultura diversificada de subsistência, agricultura diversificada com agricultura comercial, pecuária, pecuária diversificada, pecuária com agricultura comercial, pecuária de leite, pecuária de leite diversificada e pecuária de leite com agricultura comercial"

.Cada um desses tipos possui desafios e limitações próprios, utiliza diferentemente as tecnologias disponíveis, tem estrutura de renda familiar também variada.

Por razões diferentes, o contingente humano que forma a agricultura familiar, com o seu papel fundamental na composição da oferta de alimentos, foi, historicamente, romantizado por certos setores da literatura especializada. Isso produziu o enraizamento de estereótipos na compreensão das pessoas comuns e até dos técnicos, quando tratam das questões da agricultura familiar. Dessa visão romântica, como a chamam Sabbato ${ }^{13}$, surgiu uma série de deduções sem fundamentos concretos, ou as que idealizam o trabalho desses agricultores. Surgiram e persistem muitos mitos - parte deles em vias de extinção - que só colaboram para agravar o distanciamento entre a realidade desses agricultores e a imagem que, deles, é construída. Seus fundamentos são puramente ideológicos ou imaginados. A politização socialista por exemplo é um desses mitos. Mao Tse Tung p.ex., levou milhares de pessoas à fome quando insistiu em levar pessoas da cidade para os campos e para eles fornecer tratores: Quebrou séculos de uma tradição não-mecanizada da cultura do arroz e introdução de pessoas inexperientes em agricultura em campos férteis. Quando a política não está aliada ao meio ambiente e nem à comunidade, suas tradições e formas de trabalhar históricas, sempre temos situações desastrosas.

Nunca devemos imaginar que a agricultura familiar é um segmento homogêneo. Explícita ou implicitamente fundados nessa crença existem diversos programas, públicos em geral, para o desenvolvimento da agricultura familiar, mas com difícil execução, fracassos e alguns poucos sucessos pontuais. As razões do

\footnotetext{
${ }^{13}$ SABBATO, A. D. I.; BUAINAIN, A. M. Agricultura familiar e inovaçao tecnológica no Brasil: características, desafios e obstáculos. Tradução . [s.I.] UNICAMP, 2007.
} 
fracasso quase sempre nascem de uma má estratégia quanto a localidade ambiental e incorretas relações de trabalho. Isso porque é dado um tratamento homogêneo a uma realidade heterogênea.

A diversidade produtiva, sociocultural, econômica e tecnológica é uma das características mais marcantes nesse tipo de agricultura. Deve-se religar um círculo que resulta no processo pelo qual o pesquisador ou professor ensina o extensionista ou multiplicador, que, por sua vez, ensina o produtor e sua família a produzirem com variedades novas ou utilizarem novas técnicas de plantio ou de colheita.

Entretanto essa missão esconde uma questão maior, que normalmente está relacionada ao mercado e não à produção, e esse aspecto do mercado foge aos limites da natureza e das relações comunitárias. $\mathrm{Na}$ análise crítica do mito, é preciso ter em conta que, diante do problema concreto que se apresenta ao agricultor familiar, produzir é relativamente fácil. A dificuldade reside em ganhar dinheiro com a produção, isto é, ter assegurada a obtenção de uma renda líquida positiva.

$\mathrm{O}$ conhecimento autóctone, junto com melhoramentos técnicos e relações justas ambientais, legais e comunitárias deveriam ser suficientes para solucionar o problema do agricultor. Precisa-se reconhecer que o conhecimento externo científico, sem, contudo, extirpar o interno. A tecnologia tende a provocar alterações radicais nos sistemas de produção vigentes. Um agricultor não muda de sistema tecnológico simplesmente porque chegou uma novidade, mas sim porque os resultados práticos aparecem. Deve-se sempre questionar tanto a importância das tecnologias, principalmente em seus aspectos de disponibilidade, preço e viabilidade ao pequeno agricultor. Não devemos ter uma confiança cega nas tecnologias, principalmente quando não estão associadas a aspectos ambientais e comunitários. Torna-se uma crença apaixonada e unidimensional na deusa moderna: a tecnologia, como ensina o Professor Sergio Schneider ${ }^{14}$, que é importante, mas não é tudo.

Os objetivos da agricultura familiar são antagônicos aos dos agricultores do agronegócio. Essas agriculturas são distintas na forma, porém complementares nos objetivos. Ser agricultor não é apenas um estilo de vida, mas um meio de vida difícil, no qual as adversidades vão desde a própria natureza até o mercado, passando

\footnotetext{
${ }^{14}$ SCHNEIDER, S. A pluriatividade na agricultura familiar. Tradução . [s.I.] Ed. da UFRGS, 2009.
} 
pelas conhecidas políticas públicas e leis. Um país como o Brasil necessita da competitividade dos seus agroprodutos de exportação e, igualmente, da sustentabilidade de seus recursos naturais e da sua segurança alimentar. As contribuições de ambas as agriculturas são complementares e relevantes para os múltiplos interesses do País e para sua diversa população. A integração da agricultura familiar ao agronegócio têm ocorrido de forma crescente. As formas são muitas e variam conforme o produto e a região.

Luiz Otávio Cabral ${ }^{15}$ demonstrou que a agricultura familiar ressentiu-se, ao longo dos anos, de uma definição de ampla acolhida por parte dos estudiosos. Passaram se muitos anos sem consenso mínimo, principalmente no que diz respeito à sua operacionalidade. Essa não era só uma realidade acadêmica, mas um problema concreto dos que trabalhavam diretamente com projetos e programas relacionados a esse universo agropecuário. Segundo suas palavras:

"As classificações normalmente eram feitas com base no tamanho da área ou da renda. Em ambos os casos não eram suficientes para explicar as diferenças encontradas, mesmo porque a agricultura familiar tem um lado comercial significativo. É pelo comércio que ocorrem as trocas. Em casos extremos, isto é, de grande pobreza, produzir o autosustento alimentar já é um ganho. “

Manter a dignidade das famílias é, sem dúvida, uma grande conquista, no entanto, elas não precisam só de alimentos. Os não-alimentos terminam sendo tão essenciais quanto aqueles, pois a agricultura familiar precisa garantir a todos os seus membros acesso à educação, à saúde e aos mercados de bens e serviços. Por sua vez, o próprio Estado precisa assegurar esses direitos sociais básicos

Há mais informações sobre "o quê" (diagnósticos e prognósticos) deveria ser feito em agricultura familiar do que sobre "o porquê" e "o como" fazer para promover o seu desenvolvimento. Há muitos casos de sucesso, porém, em virtude da grande diferenciação (tamanho da unidade produtiva, produtos trabalhados, região na qual se localizam, são poucos os programas de possível reprodução. Os diagnósticos

\footnotetext{
${ }^{15}$ CABRAL LUIZ OTÁVIO.; SCHEIBE, L. F. Espaço e ruralidade num contexto de desenvolvimento voltado à agricultura familiar. Tradução . [s.l: s.n.].
} 
são freqüentes, cada vez mais sofisticados, volumosos, repetitivos, com excesso de variáveis analisadas, entretanto com pouca utilidade prática.

Por vezes a ciência se afastou do social. As agronomias p.ex.,caíram em um excesso de estudos sobre determinadas plantas ligadas à produção de elites e se afastou de estudos ligados à agricultura familiar. Muito se pesquisou sobre a cana ou o café, que são produtos ligados a riqueza de algumas minorias, enquanto tão pouco se pesquisou sobre a macaxeira, que é um produto ligado a grande parte da população pobre e agricultora do Brasil.

Essa visão limitada da ciência também acaba gerando uma visão limitada da lei. Ela é um produto próprio das forças políticas atuantes e como geralmente recebem a atenção de um grupo pequeno de uma elite empoderada, para lá que caminham. Só por vezes as leis refletem o que é realmente importante para o homem do campo.

No campo das leis e das políticas, são exemplos importantes o Programa Nacional de Fortalecimento da Agricultura Familiar (Pronaf), criado em 1996, o Programa de Aquisição de Alimentos (PAA) da agricultura familiar e o Programa do Biodiesel em 2008. As leis tentam acompanhar a transmutação dos desafios sociais, mas são por vezes falhas e lentas. Infelizmente por um excesso de burocracia, nossas leis não acompanham o desenvolvimento social e ambiental, gerando assim verdadeiros problemas e entraves para os agricultores.

Somos vítimas de excessos de interesses pessoais e políticos em contrariedade aos interesses sociais e ambientais. Esses últimos apenas são levados em consideração quando já estamos em nível de crise. As leis brasileiras não trabalham preventivamente e de maneira estratégica, mas apenas de maneira reativa. Isso dentro de uma lógica ambiental não faz sentido.

Na sociedade moderna, a ciência está em todo lugar. Ela não só permeia as atividades urbano-industriais, como também faz parte do cotidiano da agricultura familiar, como se desprende do livro organizado pelo professor Cazella ${ }^{16}$.

\footnotetext{
${ }^{16}$ BONNAL, P.; MALUF, R. S.; CAZELLA, A. A. Agricultura familiar: multifuncionalidade e desenvolvimento territorial no Brasil. Tradução . [s.I.] Mauad X, 2009.
} 
"Isso penetra em todos os momentos da vida das pessoas, intervindo nas suas atividades e criações, facilitando a comunicação, oferecendo mais garantias à produção agrícola, protegendo e salvando vidas. Inclusive, algumas vezes, cria alguns problemas ao mesmo tempo que resolve outros."

As ciências teriam um grande campo de investigação. P.ex., se a semente utilizada pelo agricultor familiar transporta material genético que garante, entre outras coisas, ampla resistência a pragas e doenças e à deterioração de campo; e, na capacidade de suportar o manuseio dos grãos, maior qualidade organoléptica e acentuada produtividade, como demonstrou França Neto ${ }^{17}$, em estudos relativas à soja. Nesse caso uma ciência realizada também com preocupação social teria que ter em mente uma cultura de soja que atendesse em primeiro lugar à interesses populares, em detrimento de interesses de pequenos grupos de produtores para exportação.

Introduzir uma preocupação social seria uma deturpação da própria ciência em si? Há motivos para perceber que isso é útil e desejável. Quando estamos diante de questões ambientais e de bem estar/desenvolvimento da vida humana e animal, estamos diante de desafios corretos. Tanto nossas leis quanto as ciências deveriam estar em plena atenção e preocupação com essas questões fundamentais. Desafios concretos de um mundo real.

Todas elas são características que, incorporadas na semente, indicam um dos aspectos importantes da presença de ciência e tecnologia na paisagem do campo brasileiro. Há milênios o agricultor vem domesticando diferentes variedades de plantas, num trabalho paciente e, ao mesmo tempo, eficiente em parte. Os cientistas dão prosseguimento a esse trabalho de modificação da natureza com técnicas diversas, como a hibridização. As questões problemáticas estão na sua utilidade prática e nos limites que a regras da natureza estabelecem. A bioética

\footnotetext{
${ }^{17}$ BARROS FRANÇA NETO JOSÉ DE. Qualidades fisiológica e sanitária de sementes de soja. Tradução . [s.I.] EMBRAPA, Vinculoda ao Ministério da Agricultura, CNPS, 1984.
} 
ensina $^{18}$ que só deveríamos atuar na natureza reproduzindo processos naturais. A espécie humana não tem a clarividência para perceber toda a corrente de causa e consequência que suas interferências causam e por vezes causam mais danos do que benefícios.

Em outras palavras, o ser humano não pára de intervir na transformação da natureza. Ao contrário, dois terços do planeta já experimentam profundas intervenções feitas por mudanças técnicas que geram incontáveis implicações sociais e ambientais. A natureza já não é natural, e toda mudança técnica é também social. "A natureza não é natural", que abre o livro City in a garden: environmental transformations and racial justice in twentieth-century, de Busch ${ }^{19}$, traduz a realidade que está em todo lugar.

A idéia de que existe algo "lá fora" - região selvagem, o cosmos, 'realidade' física ou biológica - que as ciências descobrem, analisam, mapeiam e manipulam é um erro, na mesma medida em que a idéia ocasionalmente esposada pelos escultores de que a estátua já se encontra na peça bruta de pedra, apenas aguardando ser revelada pelo trabalho do escultor também o é.

"Na verdade, a estátua existe somente através da atividade de esculpir. De forma similar, a natureza existe somente através de sua descrição, análise, mapeamento e manipulação. Isto não é dizer que as coisas deixam de existir sem os humanos."

No exame dessa questão é preciso ter em mente que a divisão, como conhecemos hoje, entre "sociedade", de um lado, e "natureza", de outro, é produto do século 17 , estabelecida por razões polêmicas da época, como lembra Latour ${ }^{20}$. Divisão arbitrária, assumida mais tarde (finais do século 18) pelo romantismo

\footnotetext{
${ }^{18}$ HOSSNE, William Saad. A necessidade de ensinar bioética para a formação de diferentes profissionais Disponível em: http://www.periodicos.usp.br/rdisan/article/download/83472/86431. Acessado em 27 out. 2018.

${ }^{19} \mathrm{BUSCH}, \mathrm{A} . \mathrm{M}$. City in a garden: environmental transformations and racial justice in twentieth-century Austin, Texas. Traducao . [s.I.] The University of North Carolina Press, 2017. ${ }^{20}$ The science of passionate interests: an introduction to Gabriel Tarde's economic anthropology Bruno Latour, Vincent Lépinay - Prickly Paradigm Press - 2009
} 
alemão. Para os estóicos da velha Grécia, a compreensão da natureza era colocada em termos bem diferentes. A natureza era, ao mesmo tempo, o que englobava e fornecia normas a todos. Não devemos olvidar essa visão mais global e integrativa e é necessário se afastar de uma visão pouco integrativa e limitada do homem e da natureza.

\section{RESULTADO E DISCUSSÃO}

Na busca de demonstrar em números o que foi exposto nas argumentações do presente artigo, realizamos um experimento simples, entretanto relevante nos resultados: 1) Fizemos um recorte claro: Quantas leis federais foram aprovadas no período legislativo de 2016 a 2018 que tinham como centro axiológico o meio ambiente? Para responder essa pergunta usamos as bases de dados disponíveis no site do Planalto Central.

Ao chegar em um número exato, começamos a dividir os exemplos legislativos em temáticas específicas:
a) Genética
b) Propriedade Civil
c) Proteção ambiental
d) Agricultura familiar
e) Agronegócio

Foram identificadas 263 espécies normativas, entre decretos, medidas provisórias e leis federais, divididas nessa proporção: 63 em 2018, 79 em 2017 e 121 em 2016.

Em seguida, através da análise de suas ementas e corpo normativo, as temáticas centrais puderam ser divididas desta forma: 


\begin{tabular}{lcc}
\hline Item & Quantidade & Percentual \\
\hline $\begin{array}{l}\text { leis ambientais } \\
\text { 2016-2018 }\end{array}$ & 263 & $100 \%$ \\
Genética & 34 & $12,9 \%$ \\
Propriedade Civil & 54 & $20,5 \%$ \\
Proteção ambiental & 124 & $47,1 \%$ \\
Agronegócio & 33 & $12,5 \%$ \\
Agricultura Familiar & 18 & $6,8 \%$ \\
\hline
\end{tabular}

Dos números apresentados podemos começar a tecer algumas considerações. É verdade que as ciências, as tecnologias e as leis podem promover inclusão social; entretanto, uma certa deturpação de visão está gerando baixos resultados sociais e ambientais. A degradação do nosso ambiente e uma crescente tensão social são consequências disso.

Em primeiro lugar, não se pode reivindicar neutralidade para os impactos da ciência e das leis, pois, por seu poder transformador, geram conseqüências positivas e negativas. Mas será que isso é suficiente para justificar argumentos anticiência? Deveríamos também ter leis casuísticas e totalmente direcionadas para um grupo específico, que nesse caso seria o da agricultura familiar?

Ou seria mais razoável exigir uma atividade científica isenta, com consciência crítica de sua dimensão? Deveríamos pensar em leis mais genéricas?

O presente trabalho filia-se a uma corrente de pensamento que incorporou 0 princípio da inclusão social e ambiental em todos aspectos. Temos uma visão totalmente funcionalista das atividades humanas e não acreditamos em uma teoria distante da prática e dos reais problemas ambientais e humanos.

Em segundo lugar, a exclusão social foi uma das características mais fortes da modernização seletiva no Brasil, principalmente na primeira metade do século 19. Vivemos em uma sociedade com crescentes problemas ambientais e sociais e isso é um resultado necessário diante de uma ciência e um legislativos desalinhados. 
Também não podemos deixar de questionar o quanto a ciência, feita por pessoas que por vezes não vivem as lutas e desafios do homem simples do campo, podem em alguns aspectos, ser prejudicial às práticas ancestrais daquelas comunidades. Como exemplo podemos perceber o quanto a ciência da mineralização e fertilização química do solo acabou atrapalhando a fertilização ancestral dos índios com suas tradicionais 'cabrucas' e plantios em clareiras de matas. Devemos perceber que as soluções ancestrais por vezes possuem resultados tão melhores daqueles produzidos pela ciência, mas ganham um estigma de arbitrários e pouco produtivos, por uma visão elitistas e pouco integrada da ciência e meio ambiente.

\section{CONCLUSÕES}

De tudo que foi exposto, algumas observações devem ser apuradas. As leis da natureza e da vida estão baseadas na integração de processos. O fenômeno da vida está intimamente ligada a outros processos antecedentes e subsequentes. A única forma de prosperar é se interligando de forma harmoniosa a tais processos.

Em certa medida, talvez por arrogância ou falta de uma visão holística, nossa espécie perdeu um tanto da capacidade de interagir com esses processos. Isso fica evidente nas crescentes crises ambientais e sociais que são notórias. Imaginamos por certos momentos que poderíamos interferir produtivamente nesses processos e até criar novos, mas estamos falhando terrivelmente.

Três elementos estão em destaque neste trabalho: Meio Ambiente, comunidade e Leis. O primeiro por ser o 'local' de todos os fenômenos e os dois subsequentes representando as formas de interação de nossa espécie com esse 'meio' e entre nós mesmos. Ficou notório nesses estudos que está havendo uma descompasso e baixa harmonia entre esses elementos. 
Em primeiro lugar temos uma comunidade pouco integrada e com visões antagônicas. De um lado temos uma comunidade científica que possui óbvios avanços e conquistas, mas por vezes tem uma visão limitada e elitista, já que grande parte de suas preocupações está em solucionar problemas de certas categorias e pequenos grupos de poder. Em específico nas ciências agrárias, observamos um excesso de estudos sobre cultivos relacionados a grande agronegócios, tais como a cana de açúcar, café e soja e um desdém à culturas ligadas à agricultura familiar, tais como a macaxeira ou o feijão. Além disso observamos um descompasso entre o próprio conceito de agricultura familiar e sua realidade prática e sua ideologia idílica. Além disso os saberes ancestrais das comunidades foram em grande parte soterrados por conhecimentos científicos que desmereceram as conquistas de observação de séculos de práticas. Como exemplos citamos a valorização da fertilização do solo através de processos artificiais, em detrimento de práticas ancestrais, como as indígenas, de fertilização orgânica através de clareiras nas matas, queimadas controladas e compostagem orgânica.

Através do estudo normativo, verificamos que essa limitada visão científica e essa baixa integração comunitária acabou também se refletindo nas produções legislativas subsequentes. Um grande número de leis sobre genética, propriedade e agronegócio e um baixo número de leis sobre agricultura familiar foi a consequência. As mesmas preocupações científicas limitadas, acabaram gerando também um limitado número de leis e um tanto de monotonia temática, criando um notório ambiente problematizado.

Todo esse descompasso acabou gerando uma degradação ambiental crescente e conflitos sociais potencializados. Estudos mais aprofundados são necessários para observar como essas micro-relações estão acontecendo e como podemos influenciar positivamente para que um novo círculo sinérgico aconteça. Em certa medida, a vida é uma grande dança. Nesse grande salão, algumas espécies perderam o compasso, saíram do ritmo e foram expulsas dessa dança. $A$ espécie humana parece caminhar para esse destino. Nossas comunidades, nossas leis e a forma que estamos tratando nosso ambiente é uma demonstração clara 
disso. Antes de tudo devemos perceber que essa dança não foi iniciada por nós e a nível cósmico, continuará conosco no salão ou não. Somos apenas mais uma espécie dançarina, que deve se adequar e aprender a continuar nesse grande ciclo de alegria, transformação e evolução.

\section{REFERÊNCIAS}

BARROS FRANÇA NETO JOSÉ DE. Qualidades fisiológica e sanitária de sementes de soja. Tradução . [s.l.] EMBRAPA, Vinculoda ao Ministério da Agricultura, CNPS, 1984.

BONNAL, P.; MALUF, R. S.; CAZELLA, A. A. Agricultura familiar:

multifuncionalidade e desenvolvimento territorial no Brasil. Tradução . [s.I.] Mauad X, 2009.

$\mathrm{BUSCH}, \mathrm{A} . \mathrm{M}$. City in a garden: environmental transformations and racial justice in twentieth-century Austin, Texas. Traducao . [s.l.] The University of North Carolina Press, 2017.

CABRAL LUIZ OTÁVIO.; SCHEIBE, L. F. Espaço e ruralidade num contexto de desenvolvimento voltado à agricultura familiar. Tradução . [s.l: s.n.]. 2013 CONDÉ MAURO LÚCIO LEITÃO. Ludwik Fleck: estilos de pensamento na ciência. Tradução . [s.I.] FT, Fino Traço Editora Ltda., 2012.

ČAJANOV ALEKSANDR VASILJEVIČ; SCHULZE, E.; SCHLICHTER, M. Alexander Vasilievich Chayanov: the tragedy of an outstanding agricultural 
economist. Traducao . [s.l.] AgriMedia, 2003.

GONCHAROV, A. D.; LUNIAKOV, P. I. V.I. Lenin y el campesinado: compendio histórico de divulgación. Traducao . [s.l.] Agencia de Prensa Nóvosti, 1969. GÖTSCH ERNST. Break-through in agriculture. Tradução . [s.I.] AS-PTA, 1995. HOSSNE, William Saad. A necessidade de ensinar bioética para a formação de diferentes profissionais Disponível em:

http://www.periodicos.usp.br/rdisan/article/download/83472/86431. Acessado em 27 out. 2018.

KAUTSKY, K.; BAYO, C.; UNAMUNO, M. D. E. La Cuestión agraria: (Die agrarfrage). Tradução . [s.I.] Viuda de Rodríguez Serra, 2016.

KAUTSKY, K. La cuestión agraria: análisis de las tendencias de la agricultura moderna y de la política agraria de la socialdemocracia. Traducao . [s.I.] Siglo Veintiuno, 1989.

LATOUR, B.; LÉPINAY VINCENT ANTONIN. The science of passionate interests: an introduction to Gabriel Tarde's economic anthropology. Traducao . [s.I.] Prickly Paradigm Press, 2009.

MALUF, Renato Sérgio. Resenha Bibliográfica 1 - Portal de Revistas da USP. Disponível em:

https://www.revistas.usp.br/ee/article/viewFile/117065/114680. Acessado em 10 out. 2018.

R. TATIANA LÓPEZ; FRIEDMANN, A. Análisis presupuestario del Ministerio de Agricultura y Ganadería 1998 al 2000. Tradução . [s.I.] CEPPRO, 2001. SOUSA, I. S. F. DE (ED.). Agricultura familiar na dinâmica da pesquisa agropecuária. Tradução . [s.l.] Embrapa Informações Tecnológicas, 2007. SABBATO, A. D. I.; BUAINAIN, A. M. Agricultura familiar e inovaçao tecnológica no Brasil: características, desafios e obstáculos. Tradução . [s.I.] 
UNICAMP, 2007.

SCHNEIDER, J. E. Integração de mercados e desafios para a pesquisa agropecuária Mercosul e União Européia. Tradução . [s.I.] EMBRAPA-CPACT, 1995.

SCHNEIDER, S. A pluriatividade na agricultura familiar. Tradução . [s.I.] Ed. da UFRGS, 2009.

SOBRINHO J. FALCÃO. Semi-árido diversidades, fragilidades e potencialidades. Tradução . [s.I.] Sobral Gráfica, 2006.

SOUSA IVAN SÉRGIO FREIRE DE. A sociedade, o cientista e o problema de pesquisa: o caso do setor público agrícola brasileiro. Tradução . [s.I.] Ed. Hucitec, 1993.

SOUZA IVAN SÉRGIO FREIRE.; CABRAL JOSÉ RENATO FIGUEIRA. Ciência como instrumento de inclusão social. Tradução . [s.I.] Embrapa Informação Tecnológica, 2009. 